\title{
MEDITERRANEAN SURFACE GEOSTROPHIC CIRCULATION FROM SATELLITE DATA
}

\section{CIRCULACIÓN GEOSTRÓFICA EN SUPERFICIE EN EL MAR MEDITERRÁNEO A PARTIR DE DATOS DE SATÉLITE}

\author{
Ferdous Zid*, Isabel Vigo, David García \\ Department of Applied Mathematics, University of Alicante, Carretera San Vicente del Raspeig s/n, 03690 San Vicente del Raspeig, \\ Spain.zf5@gcloud.ua.es; vigo@ua.e; d.garcia@ua.es
}

\begin{abstract}
:
In this work, we provide an updated geodetic approach to the Mediterranean Surface Geostrophic circulation based on satellite data. We follow same methodology as in a previous approach by Vigo et al. (2018), but here both the Sea Surface Height $(\mathrm{SSH})$ and the Geoid $(\mathrm{N})$ have been updated by enhanced solutions, and the time period covered has been extended to 23 years, from 1993 to 2015 . The main general pattern of circulation is confirmed with respect to previous approach, but the new estimation provides enhanced resolution of the details, and higher variations in the climatology. When compare both satellite data-based approaches to the Mediterranean Surface Geostrophic Circulation (SGC) with Mercator model simulations that assimilates in-situ measurements, our new estimate shows clearly better agreement than the earlier approach. The mean circulation for the studied period, and the climatology of the SGC for the Mediterranean Sea are presented in the context of previous literature.
\end{abstract}

Key words: Mediterranean sea circulation, ocean geostrophy, mean dynamic topography, satellite gravimetry, satellite altimetry, remote sensing

\section{Resumen:}

En este trabajo, proporcionamos una actualización de la circulación geostrófica en superficie del Mediterráneo obtenida a partir de datos de gravedad y altimetría desde satélite. Seguimos la misma metodología que en un enfoque anterior de Vigo et al. (2018), pero aquí tanto la altura de la superficie del mar (SSH) como el geoide (N) se han actualizado usando soluciones mejoradas, y el período de tiempo cubierto se ha ampliado a 23 años, de 1993 a 2015. El patrón general de circulación se confirma con respecto a la aproximación anterior, pero esta nueva estimación proporciona una resolución mejorada en los detalles de pequeña escala, así como mayores variaciones en la climatología. Cuando se comparan ambos enfoques basados los dos en datos satelitales para la Circulación Geostrófica de la Superficie del Mediterráneo (SGC) con las simulaciones del modelo Mercator (que asimila las mediciones in situ), nuestra nueva estimación muestra claramente una mejor concordancia que la aproximación anterior. La circulación media para el período estudiado y la climatología del SGC para el mar Mediterráneo se presentan en el contexto de la literatura previa.

circulación del Mar Mediterráneo, geostrofia oceánica, topografía dinámica media, gravimetría satelital, altimetría satelital, teledetección

Palabras clave: circulación del Mar Mediterráneo, geostrofia oceánica, topografía dinámica media, gravimetría satelital, altimetría satelital, teledetección

\section{Introduction}

In the recent years the determination of the geoid has experience a remarkable improvement in terms of accuracy and spatial resolution thanks to the availability of satellite data, mainly from space missions such as the ESA mission Gravity field and steady-state Ocean Circulation Explorer (GOCE), or the NASA and DLR mission Gravity Recovery and Climate Experiment (GRACE) and its Follow-On. Also our knowledge of the Sea Surface Height (SSH) has improved, given the availability of new satellite missions. This translates in enhancements on the geodetic estimation of the ocean Absolute Dynamic Topography (ADT), and therefore on the geostrophic currents derived from that.
Thus, in this work we will revisit the first approach given by Vigo et al. (2018) to the Surface Geostrophic Circulation (SGC) in the Mediterranean Sea based entirely on satellite data from gravity and altimetry missions by providing an estimate of the SGC following the same methodology but with an improved Mean Dynamic Topography (MDT) and enhanced SSH. We will use the new geodetic Mean Dynamic Topography model DTU19MDT from the Danish National Space Center (Knudsen et al. 2020) that is obtained from the OGMOC geoid model (augmented using the EIGEN-6C4 coefficients to d/o 2160), and it has been derived using this geoid model and the DTU18MSS mean sea surface Andersen et al. (2018). And the new release of sea level maps provided by the $\mathrm{CCl}$-Sea Level Project from several altimetry satellites (Jason 1\&2, Topex/Poseidon, Envisat,

*Corresponding Author: Ferdous Zid, zf5@gcloud.ua.es 
ERS1\&2, GFO). The time period has also been extended, with respect to the previous approach, spanning from 1993 to 2015.

\section{Data and Methodology}

The Surface Geostrophic Currents can be estimated based on only satellite observations. On one side, satellite gravity data, mainly from GOCE Mission, provide us an accurate approach of the Geoid $(\mathrm{N})$ with high spatial resolution. On the other side, the multiple satellite altimetry missions allow us to measure precisely the SSH. Thus, defining the Absolute Dynamic Topography (ADT) as Ec. (1):

$$
\operatorname{ADT}(x, y, t)=\operatorname{SSH}(x, y, t)-N(x, y)
$$

where $N$ is a time averaged geoid, $x$ and $y$ stands for the longitude and latitude respectively, $t$ represents the time and SSH identifies the Sea Surface Height. The vector field of the SGC, with $u_{s}$ being the zonal component of the velocity (positive eastward) and $v_{s}$ the meridional component (positive northward), follows from the geostrophic equation, that is, the balance between the pressure gradient and the Coriolis forces, Ecs. (2) and (3)

$u_{s}(t)=-\frac{g}{f} \frac{\partial A D T}{\partial y}$

$v_{S}(t)=\frac{g}{f} \frac{\partial A D T}{\partial x}$

where $g$ is the gravitational acceleration, $f=2 \omega \sin \phi$ is the Coriolis frequency, which depends on the latitude $\phi$ ( $\omega$ represents the rate of rotation of the Earth).

In this work, as for the SSH, measured by altimetry missions, we will use the dataset provided by the CCl-Sea Level Project (http://www.esa-sealevel-cci.org) as a monthly merged solution from several altimetry satellites (Jason 1\&2, Topex/Poseidon, Envisat, ERS1\&2, GFO), covering the time span 1993/01/01 to $2015 / 12 / 31$, and with a spatial resolution of $1 / 4$ by $1 / 4$ degree (Product Version 1.1). All recommended geophysical and atmospheric corrections have been applied to the data. This product consists of Sea Level Anomalies (SLA), with respect to a Mean Sea Surface (MSS), we obtain the SSH by restoring back the MSS. The MSS product is the DTU18MSS: The high-resolution mean sea surface model DTU18MSS provided by the Danish National Space Center (Andersen et al. 2018), based on 25 years of multi-mission satellite altimeters from several different satellites, including 3 years of Sentinel-3A and an improved 7 years Cryosat-2 LRM record.

Regarding to $\mathrm{N}$, in this approach we use the GOCEOGMOC (Optimal Geoid Modelling based on GOCE and GRACE third-party mission data and merging with altimetric sea surface data to optimally determine Ocean Circulation) augmented using the EIGEN-6C4 coefficients to $d / o 2160$. This new geoid model will improve resolution of the details since it has been optimized to avoid striations and orange skin like features (Gruber and Frecher 2018). We recover it from the the new geodetic Mean Dynamic Topography model DTU19MDT from the Danish National Space Center Knudsen et al. (2020) that is obtained from the OGMOC geoid model and the DTU18MSS MSS.

As a result, we obtained the SGC vector fields as monthly maps of the zonal and meridional components of the
Mediterranean Geostrophic Circulation in the surface with a spatial resolution of $1 / 4$ degree and covering the time period from January 1993 to December 2015.

\section{Results and Discussion}

In this section, we present the results for the Mean Mediterranean SGC for the 23 years period 1993-2015, and its monthly climatology and seasonal variations. The Mediterranean circulation pattern shows two sub-basins naturally divided, that are the Western and Eastern or Levantine basins. To present the results, we consider these two sub-basins, and a third region that we refer as the Mediterranean Central region, and it comprises the Tyrrhenian and the lonian seas. This work is an update of Vigo et al. (2018); thus, we focus the discussion on a comparison with previous results therein. In Figure 1a. is included a schematic map of the main pattern of the Mediterranean surface circulation, characterized by a large amount of mesoscale variability phenomena.

In Figure 1b, we represent our approach of the flow vector field, direction of the mean vectors overlapped to their norm. Most of the major mesoscale features in the circulation are cancelled out when computing the mean, we analyse those, later in this section, by considering the anomalies with respect to this mean.

In the latter subsections, we present the monthly climatology of SGC as anomalies respect to the mean (shown in Fig. 1b) to capture the seasonal variability of the SGC; The SGC anomalies variations group by seasons (winter, spring, summer and autumn) for the different three regions (Western sub-basin, Central region and Eastern sub-basin) are examined later in subsection 3.3.

\subsection{Mean Mediterranean SGC}

Our results confirm the mean SGC shown in Figure 1a, that is in good agreement with previous studies of the general pattern of the Mediterranean Sea circulation (Robinson et al. 1991, 1999; Poulan et al. 2012). The general circulation of the Mediterranean Sea is mainly characterized by the Atlantic Water Jet with its instabilities, bifurcations and multiple veins, which travels from west (Gibraltar basin) to east (Levantine basin) Robinson et al. (2001); Due to its geographic location the Atlantic water inflow travels over the southern part all of the Western, the Ionian and the Levantine basins identifying several important features along the coast such as the Alboran gyres which appears with higher intensity in the mean circulation (Fig. 1b), Algerian currents creating some eddies and branches up to the Balearic sea, going to the southern part of the eastern basin Mersa-Martuh eddies and the lerapetra and Pelops gyres are clearly identified in Figures $1 \mathrm{~b}$ and $1 \mathrm{c}$ with mean speed reaching up to $28.5 \mathrm{~cm} / \mathrm{s}$, move eastward to the Sardinia Channel where two streams of water enter the eastern basin through the Sicily Strait: the Atlantic Tunisian Current (ATC), first reported by Béranger et al. (2004), traveling along the Tunisian coast, and the Atlantic-lonian Stream (AIS) flowing off the southern coast of Sicily. The latter has a branch northward that becomes the Mid-Ionian Jet (MIJ), and a second branch turns south-eastward and merges with Bifurcation of the ATC (BATC) close to Lampedusa Island depending on the season it could be just BATC or mainly AIS as we will see latter. 


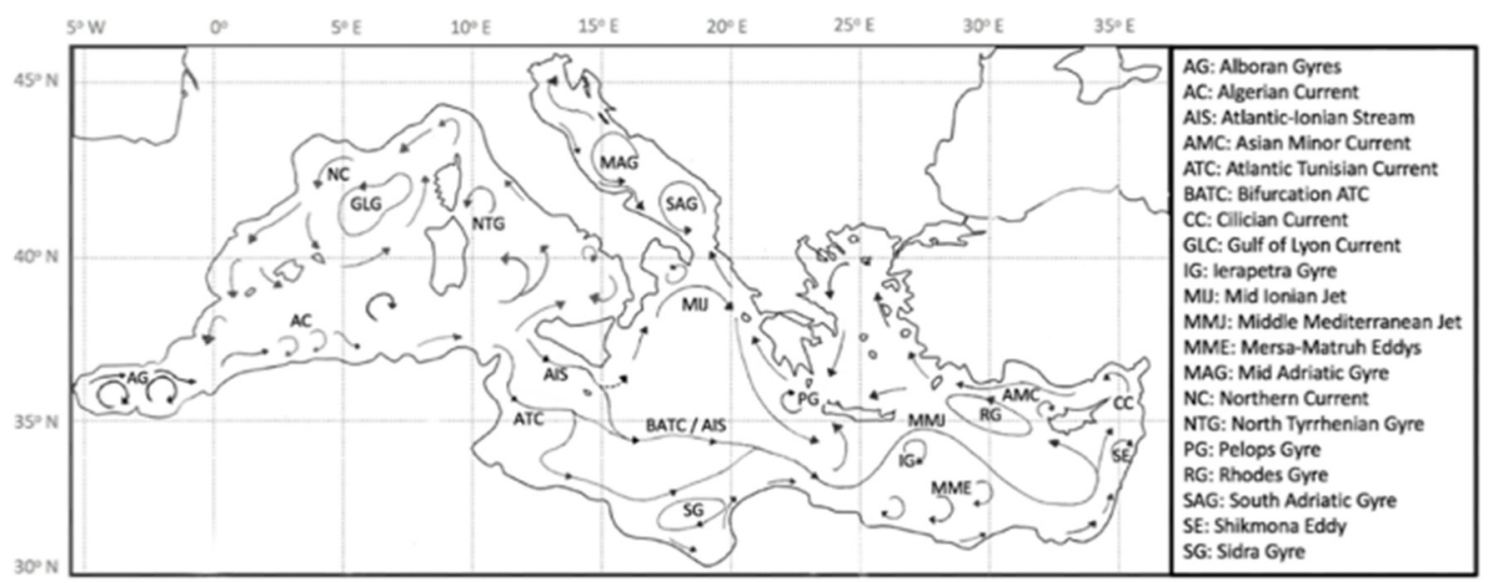

(a)

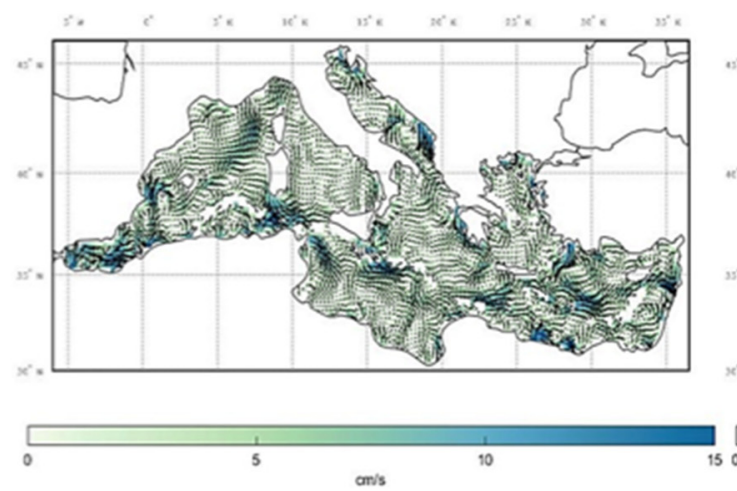

(b)

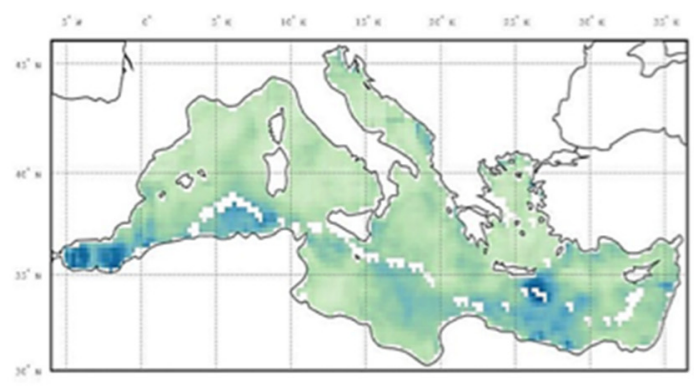

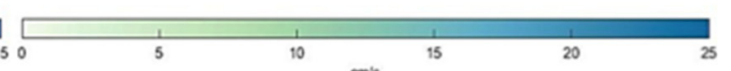

(c)

Figure 1: Mean Mediterranean Surface Circulation: a) Schematic map of Mean Mediterranean Circulation from (Vigo et al. 2018), reproduced with authors permission; b) Mean Mediterranean SGC flow field for the period 1993-2015, direction (arrows) superposed to their norm (shading, in $\mathrm{cm} / \mathrm{s}$ ); c) Mean monthly Mediterranean SGC Speed (in $\mathrm{cm} / \mathrm{s}$ ).

\subsection{Monthly Climatology and Seasonal Variations}

The monthly climatology of the SGC is represented in Figures 2 and 3 as monthly maps of anomalies with respect to the mean shown in Figure $1 b$; they catch the seasonal variation of the general pattern of circulations, in general, follows in good agreement the results in Vigo et al. (2018), thought here we can observe better the detail in the small-scale phenomena, and higher variations with respect to the previous approach in almost all the main currents.

Many seasonal variations for some of the Mediterranean Sea mesoscale features can be identified as we will discuss later by regions. For a better visualization of this mesoscale features seasonal variations, we present the results by zooming in by regions. Therefore, in the following, we analyse the four seasons for the Western Mediterranean (Fig. 4); the Central region including Tyrrhenian and Ionian Sea (Fig. 5); and the Eastern Mediterranean (Fig. 6). The four maps (one per season) represented on each figure correspond to the 1993-2016 mean according to the following season definition: Winter (December, January, February); Spring (March, April, May); Summer (June, July, August); Autumn (September, October, November).

\subsubsection{Western basin}

The main features in the western basin are the Alboran gyres $(A G)$ and the Algerian Current $(A C)$ circulation, as observed in Figure 2 two strong cyclonic AG appears in the west southern part and a third one with less intensity appears around ( $1^{\circ}$ East, $37^{\circ}$ North) in both seasons winter and spring, at the same location all the AG changes its direction into anticyclonic gyres in summer and autumn when the third gyre remains with the same direction with lower speed, our findings appears to be partly substantiated by our previous work Vigo et al. (2018).

As shown in Figure 4, the AC flows eastward along the Algerian coast with a speed increase of around 12-13 $\mathrm{cm} / \mathrm{s}$ only in winter time, and slows down the rest of the year, the flow emerges nesting small meanders along the coast in all seasons northward to Sicily Island; Noticing remarkable changing in direction west ward in the summer season of the $A C$, these changing appears strongly in August and June (see Fig. 2), remarking also a permanent appearance of the Gulf of Lyon Current with higher visualization in winter and spring seasons; As we estimated only the geostrophic circulation, the past studies often referred to the total circulation, it is well known that the Alboran Sea upper layer circulation behaviour is driven by wind stress and atmosphere pressure is largely ageostrophic, see Viudez et al. (1996, 1998).

The observed seasonal reversal in the western basin, thus need to be interpreted with caution considering the high variability of the mesoscale phenomena and the difficulty to validate it with in situ observations in the region given the lack of literature about it. 
$5^{\circ} \mathrm{W} \quad 0^{\circ} \quad 5^{\circ} \mathrm{E} 10^{\circ} \mathrm{E} 15^{\circ} \mathrm{E} 20^{\circ} \mathrm{E} 25^{\circ} \mathrm{E} 30^{\circ} \mathrm{E} 35^{\circ} \mathrm{E} 5^{\circ} \mathrm{W} \quad 0^{\circ} 5^{\circ}$ E1 $0^{\circ}$ E1 $5^{\circ}$ E2 $0^{\circ} \mathrm{E} 25^{\circ} \mathrm{E} 30^{\circ} \mathrm{E} 35^{\circ} \mathrm{E}$
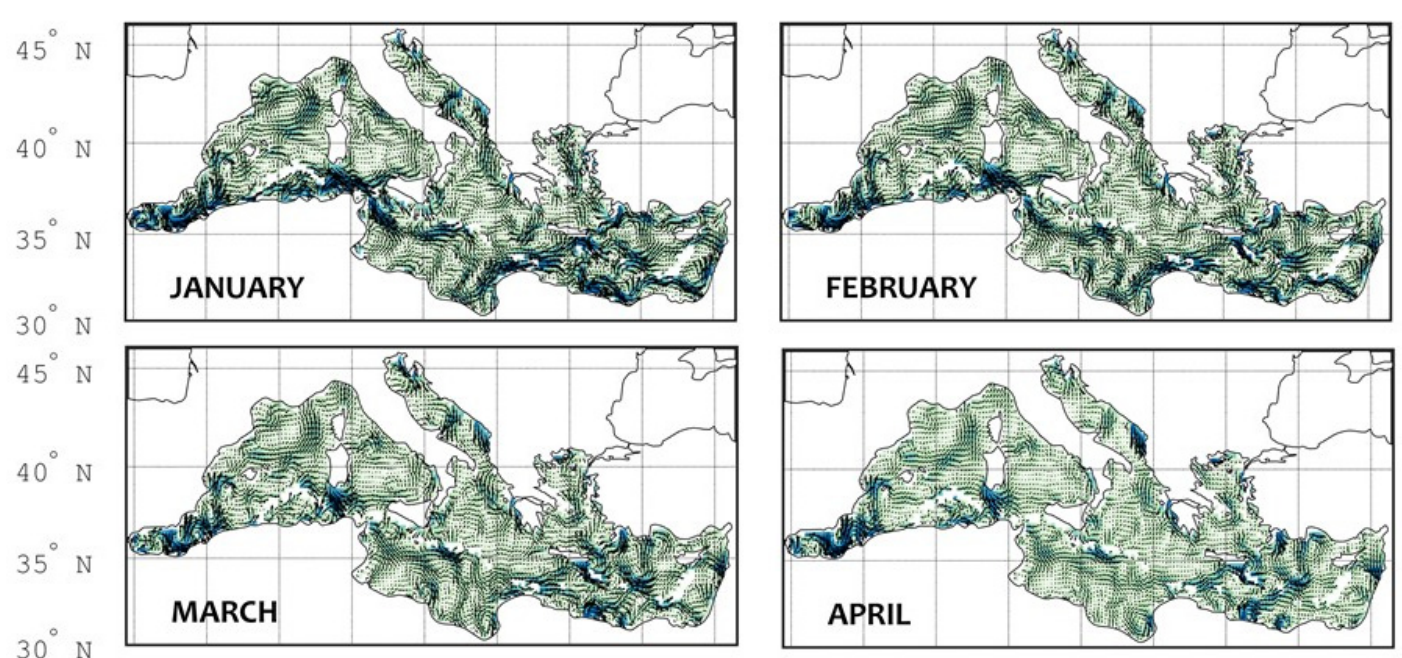

$45^{\circ} \mathrm{N}$
$40^{\circ} \mathrm{N}$
$35^{\circ} \mathrm{N}$
$30^{\circ} \mathrm{N}$
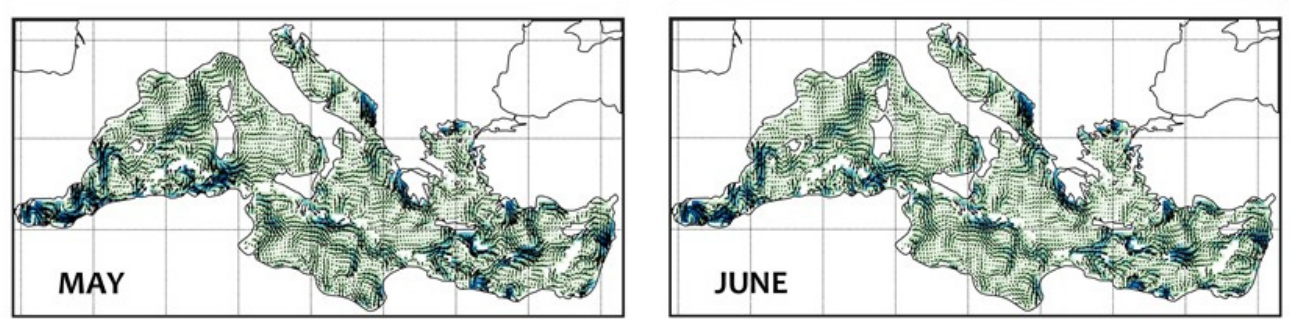

0

10

15

Figure 2: Monthly climatology of the Mediterranean Surface Geostrophic Currents anomalies with respect to the 1993-2015 mean (shown in Figure 1a). Months from January to June, the month is indicated at the right bottom of each panel.

$5^{\circ} \mathrm{W} \quad 0^{\circ} 5^{\circ} \mathrm{E} 10^{\circ} \mathrm{E} 15^{\circ} \mathrm{E} 20^{\circ} \mathrm{E} 25^{\circ} \mathrm{E} 30^{\circ} \mathrm{E} 35^{\circ} \quad 5^{\circ} \mathrm{W} \quad 0^{\circ} \quad 5^{\circ}$ E1 $10^{\circ}$ E1 $5^{\circ}$ E2 $0^{\circ}$ E2 $5^{\circ}$ E $30^{\circ} \mathrm{E} 35^{\circ}$
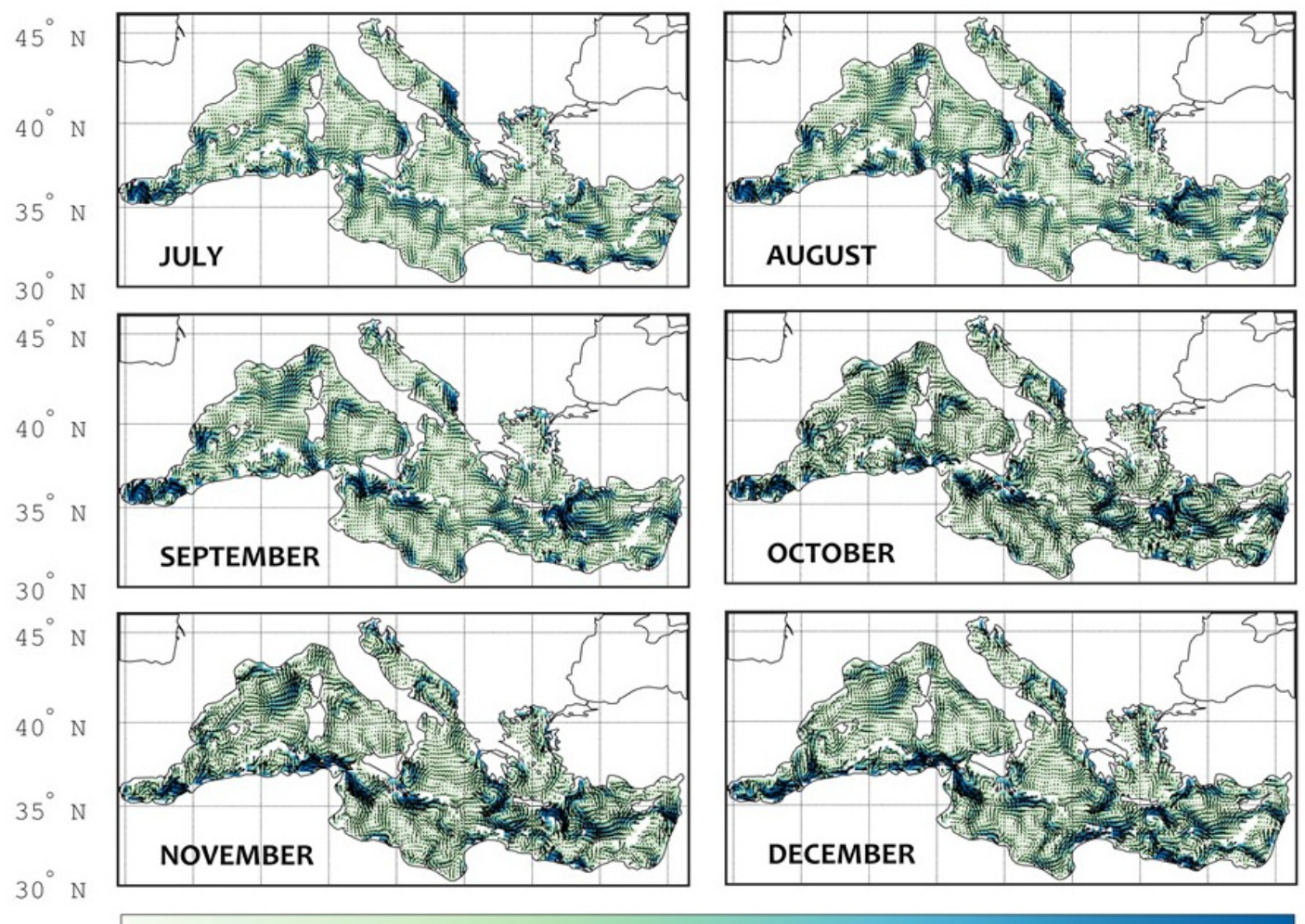

0

10

15

Figure 3: Monthly climatology of the Mediterranean Surface Geostrophic Currents anomalies with respect to the 1993-2015 mean (shown in Figure 1a). Months from July to December, the month is indicated at the right bottom of each panel. 


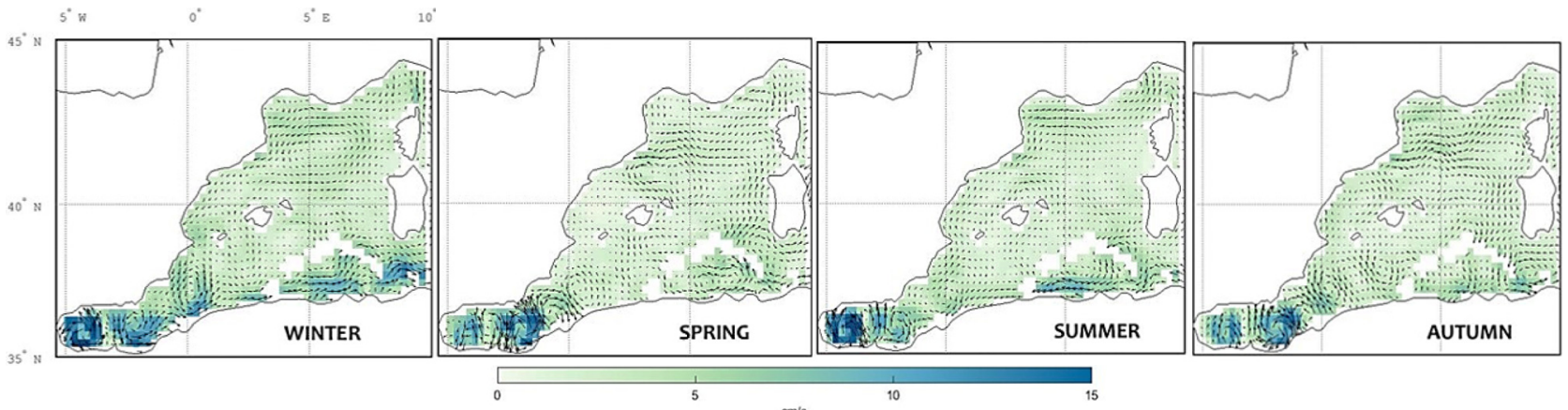

Figure 4: 1993-2015 Seasonal Mean Western Mediterranean Surface Geostrophic Currents as estimated from satellite data. Season is indicated at the bottom left of each panel. The colour scale is designed to better visualize the full range of values and it's saturated to 15 $\mathrm{cm} / \mathrm{s}$, though speed reaches up to $18.6 \mathrm{~cm} / \mathrm{s}$.

$10^{\circ} \mathrm{E} \quad 15^{\circ} \mathrm{E} \quad 20^{\circ} \mathrm{E}$
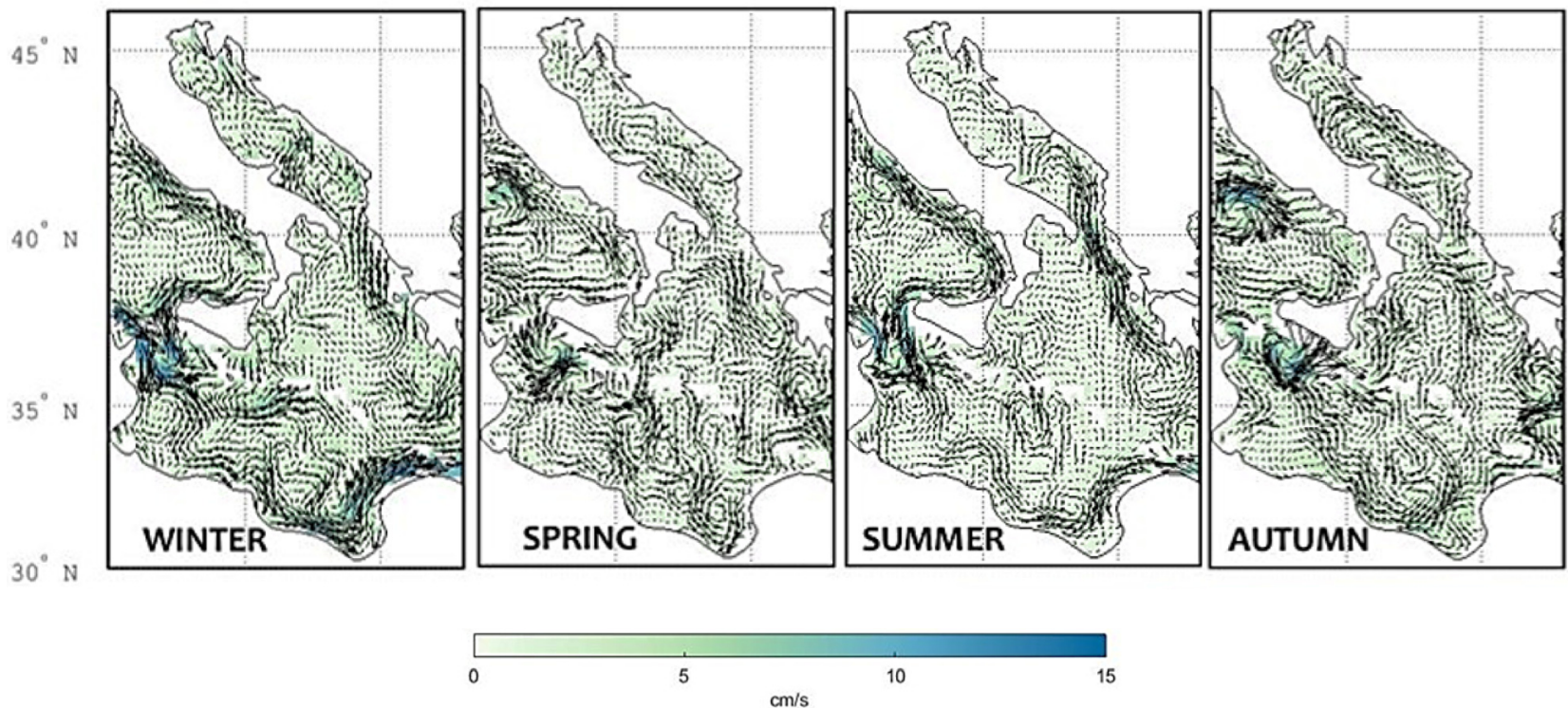

Figure 5: 1993-2015 Seasonal Mean Surface Geostrophic Currents in the Central Mediterranean region estimated from satellite data Season is indicated at the bottom right of each panel. The colour scale is designed to better visualize the full range of values and it's saturated to $15 \mathrm{~cm} / \mathrm{s}$, though speed reaches up to $16.5 \mathrm{~cm} / \mathrm{s}$.

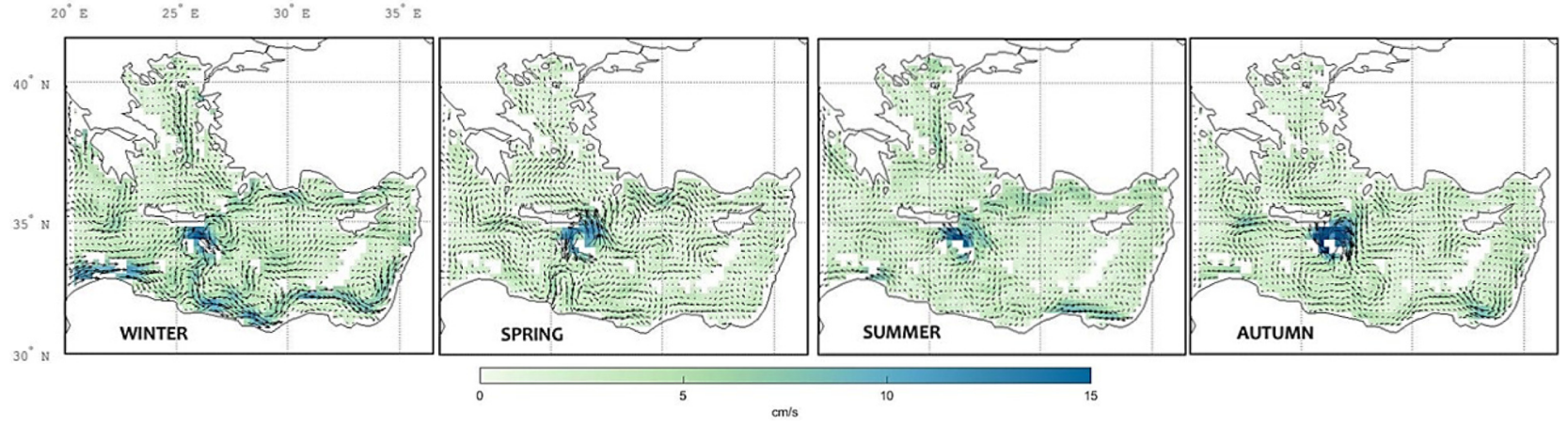

Figure 6: 1993-2015 Seasonal Mean Eastern Mediterranean Surface Geostrophic Currents as estimated from satellite data. Season is indicated at the bottom left of each panel. The colour scale is designed to better visualize the full range of values and it's saturated to 15 $\mathrm{cm} / \mathrm{s}$, though speed reaches up to $18 \mathrm{~cm} / \mathrm{s}$.

\subsubsection{Central region}

Figure 5 focuses on the central region of the Mediterranean Sea located between longitude lines $10^{\circ}$ and $25^{\circ}$ east. Circulation in this area is characterized by a branch of the AIS that travels cyclonically toward the north, in autumn the Tyrrhenian gyre is confined north of the Bonifacio Strait and has a definite zonal orientation and nested smaller eddies inside, in summer the current at the frontal region increases while the gyre is stretched out to the north as far as the central Tyrrhenian Sea specially in May and June reversing its direction in September as shown in Figures 2 and 3.

This reversal also reported in Vigo et al. (2018) was not mentioned in the earlier literature, although there is an 
agreement in the general pattern of the Tyrrhenian gyre with Artale et al. (1994).

The southern Tyrrhenian sub basin is characterized by a branch of the AIS that reaches its maximum velocity in both winter and summer when its norm exceeds the 15 $\mathrm{cm} / \mathrm{s}$, it's mainly influenced by outside circulation conveyed into the sub basin through Strait of Sicily, where we notice a strong motion of AIS and ATC with high anomalies around $14.5 \mathrm{~cm} / \mathrm{s}$ in winter and $13-10 \mathrm{~cm} / \mathrm{s}$ in the rest of the year. This merging creates a dipole composed of cyclonic and anticyclonic circulation, see Marullo et al. (1994).

The Adriatic general circulation system is confirmed as a global cyclonic circulation except in the northern Adriatic area where an anticyclonic meanders going northeast direction towards Trieste in autumn, winter and spring, nevertheless it flows out southeast direction along Greece coast with higher strength that reaches up to $15 \mathrm{~cm} / \mathrm{s}$ in summer season forming Pelops seasonally gyre with low velocity around $2-5 \mathrm{~cm} / \mathrm{s}$ in June as shown in Figure 2, a similar observation in different periods has been reported by Artegiani et al. (1997) and Poulain (2001).

\subsubsection{Eastern basin}

In the eastern Mediterranean Basin shown in Figure 6 several seasonal variations are observed regarding the Middle Mediterranean Jet (MMJ), lerapetra Gyre (IG) and the Mersa-Martuh Eddies (MME), both of MMJ and IG shift their position seasonally with higher velocities in the central part of Levantine Sea, reporting a cyclonic lerapetra Gyre in both seasons spring and summer, shifting into a cyclonic gyre in autumn at the same spot, the southern vein flows eastward from the edge of Tunisian and Libya coast noticing an increment of velocity in winter shifting westward direction in summer with less intensity forming the MME with stronger speed in winter and spring, the seasonal reversal is in a good agreement with our previous work Vigo et al. (2018).

The velocity vector field reveals a basin-scale cyclonic circulation along the shelf slope in the Levantine basin in winter and spring with average speed that reaches to 16 $\mathrm{cm} / \mathrm{s}$, while the southern part appears to be dominated by mesoscale eddies, the last gyre series seem to be generated by the instability of the coastal current and its interaction with the Mersa- Matruh continental shelf (29$30^{\circ}$ East). It seems that these interactions intensify the eddy signature and increase its size in winter. Then, it sheds the coastal current and propagates seaward (north-eastward) across the Shikmona area.

Along the eastern Levantine coasts, the northward stream meanders and generates many eddies, gets stronger and larger in winter, precisely in December and January, although it remains motionless in several months of the year as April and May (see Figs. 2 and 3). This feature is similar to the behaviour of the AC reported earlier. As for the AG, this apparent discrepancy can be partly explained by the strong ageostrophic component of the IG due to the Etesian winds see (Mkhinini et al. 2014). This results share a number of similarities with Alhammoud et al. (2005) and also confirms our previous finding Vigo et al. (2018).

\subsection{Comparison with Mercator data}

In this section we compare our results with the SGC from the hydrodynamic model Mercator that assimilates in situ, SST and altimetry data. For the comparison, we will consider only the 7 years period from 2007 to 2013, in order to consider the same period as in Vigo et al. (2018) and make easier to evaluate the enhancement of the new approach. In Figure 7 we have plotted the standard deviation of Mediterranean SGC speed for that period. Notice that the colour scale is designed to resolve regional features rather than extreme values and saturates at $15 \mathrm{~cm} / \mathrm{s}$. It confirms for this sub-period the variability follows the same behaviour commented on the former analysis of the annual climatology (Figs. 2 - 6).

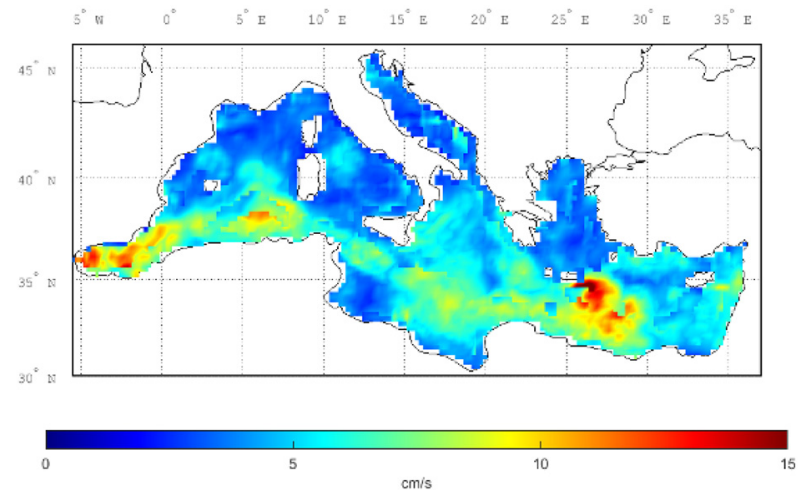

Figure 7: Standard deviation of the Mediterranean Surface Geostrophic Currents speeds as estimated from satellite data for the period 2007-2013.

Comparing our approach with the Mercator SGC, we find that the annual mean speed Mercator SGC Climatology (not shown) presents a similar pattern that our approach, but with higher velocities southeast of Crete, where the IG forms, and in the western part of the Alboran Sea, where the first $A G$ takes place. We have estimated the correlation between the mean SGC speed from both datasets restricted to the Mercator period and the correlation between two maps is 0.61 (statistically significant at the 0.05). That is a remarkable increase in the correlation with Mercator simulations with respect to the previous approach (whose mean SGC correlation with Mercator mean SGC was 0.46). This increase on correlation offers a compelling evidence for the improvement of our updated approach and confirms again the validity of the methodology and the data, to capture not only the general pattern of circulation, but also small-scale circulation features, as is the case of the Mediterranean Sea circulation.

The mean SGC speed for both data sets (not shown) is in very good agreement showing the same pattern all over, but quantitatively it shows much better agreement in the Eastern and south of the Western basin (where the main variability takes place), while in the north part mean velocities are lower in our SGC approach, the main differences are in the coastline of Gulf of Lion and north part of the Balearic basin.

In Figure 8, we have represented the map of correlation coefficients between the mean Mercator SGC speed and our approach, where correlation values ranging between mainly 0.6 and 0.8 are observed all over, reaching up to 1 in some spots located at along the main path of the Atlantic Stream System. 


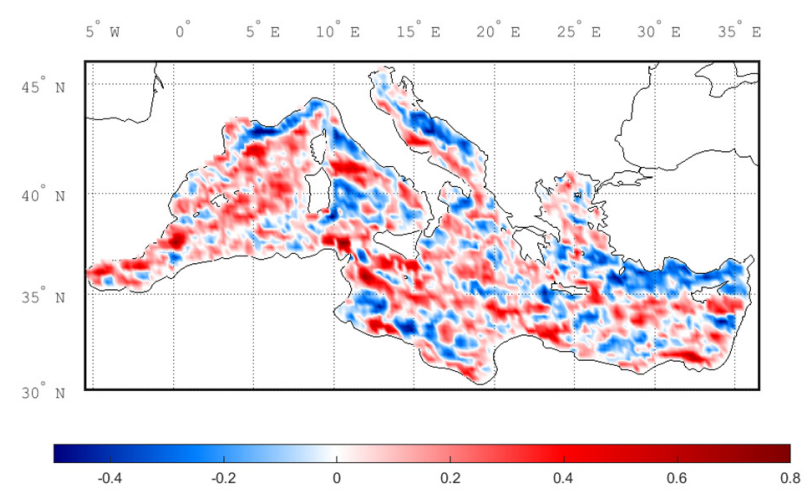

Figure 8: Correlation coefficients map between the Mediterranean Surface Geostrophic Currents Speed as estimated from satellite data and from ocean model Mercator simulated data (time period 2007-2013).

\section{Conclusions}

This study provides an improved geodetic approach, based on satellite data, to the Mediterranean SGC and its climatology. Our estimated mean SGC reproduces the general known patterns of the Mediterranean Sea Circulation at the basin and sub basin scale (Robinson et al. 1991, 1999; Roussenov et al. 1995; Millot and TaupierLetage 2005; Poulain et al. 2012) beside reporting new findings and enhancing the methodology and data sets used in our previous work Vigo et al. (2018).

For both the Western and Eastern basins, seasonal variations of the circulation are observed for well-marked events such as the $A C$ and $A G$ seasonal reversal for the first, and the IG for the latter, confirming our previous results and other studies such as: (Alhammoud et al. 2005; Artegiani et al.1997; Poulain 2001; Marullo et al. 1994). The central region is characterized by the AIS and the Adriatic circulation system with three gyres that vary seasonally reported, what partly supports previous studies as Marullo et al. (1994). For the Eastern basin, dominated by the MME, MMJ and the IG, we present a seasonal variation that shares a similarity with Alhammoud et al. (2005) and also confirms our previous results Vigo et al. (2018).

The outcomes presented for the Mediterranean must be interpreted with caution, given the high variability and the small scale phenomena that characterize the Mediterranean Sea, as well as their possible ageostrophic nature. Unfortunately, the limited availability of in situ observations doesn't allow a full validation of the results. Nevertheless, considerable progress has been made with regards to comparison with Mercator model simulations that assimilate in situ data among other. A noticeable improvement in the correlation with Mercator simulations has been reported with respect to our previous approach, we obtained also similar patterns and intensities for the main characteristics at basin and sub basin scales for the seasonal variations. Thought our approach currents intensities are still weaker that those provided by Mercator simulations, mainly in the northern part of the Western basin.

In this work, the incorporation of an enhanced SSH and a more accurate geoid, allowed to provide improved geodetic estimates of the Mediterranean SGC from satellite data only. This represent an evaluation tool for studying ocean dynamics at the basin and sub-basin scales, where further efforts need to be made.

\section{Acknowledgements}

We acknowledge the support of all data providers: ESA $\mathrm{CCI}$ Sea Level Project for the Altimetry data, DTU SPACE from the Danish National Space Centre for MDT and MSS products, the surface currents from the Mercator Ocean Project, and LEGOS and CERSAT for the Ekman Surface Currents. The work is supported by Spain Ministry of Science, Innovation and Universities grant number RTI2018-093874-B-100. Zid Ferdous is supported by PhD Grant of Ministry of Higher Education and Scientific Research from Algerian Government for residential training abroad.

\section{References}

ALHAMMOUD, B., BÉRANGER, K., MORTIER, L., CRÉPON, M., and DEKEYSER, I., 2005. Surface circulation of the Levantine Basin: comparison of model results with observations. Progress in Oceanography, 66(2-4), pp. $299-320$.

ANDERSEN, O., KNUDSEN, P., and STENSENG, L., 2018. A new DTU18 MSS mean sea surface-Improvement from SAR altimetry. In 25 years of progress in radar altimetry symposium.

ARTALE, V., ASTRALDI, M., BUFFONI, G., and GASPARINI, G. P., 1994. Seasonal variability of gyre-scale circulation in the northern Tyrrhenian Sea. Journal of Geophysical Research: Oceans, 99(C7), pp. 14127-14137.

ARTEGIANI, A., PASCHINI, E., RUSSO, A., BREGANT, D., RAICICH, F., and PINARDI, N., 1997. The Adriatic Sea general circulation. Part II: baroclinic circulation structure. Journal of physical Oceanography, 27(8), pp. 1515-1532.

BÉRANGER, K., MORTIER, L., GASPARINI G.-P, GERVASIO, L., ASTRALDI, M., and CRÉPON, M., 2004.The dynamics of the Sicily Strait: a comprehensive study from observations and models, Deep Sea Research Part II: Topical Studies. Oceanography, 51(4-5), pp. 411-440.

GRUBER, T., and FECHER, T., 2018. Optimal Ocean Geoid as Reference Surface for Mean Ocean Circulation and Height Systems. In EGU General Assembly Conference Abstracts, p. 8691.

KNUDSEN, P., ANDERSEN, O., and MAXIMENKO, N., 2019. A new ocean mean dynamic topography model, derived from a combination of gravity, altimetry and drifter velocity data. Advances in Space Research.

MARULLO, S., SANTOLERI, R., and BIGNAMI, F., 1994. Tyrrhenian Sea: Historical Satellite Data Analysis. Seas. Interannu. Var. West. Mediterr. Sea, 46, pp. 135-154. 
MILLOT, C., and TAUPIER-LETAGE, I., 2005. Circulation in the Mediterranean Sea. In The Mediterranean Sea, pp. 2966. Springer, Berlin, Heidelberg.

MKHININI, N., COIMBRA, A. L. S., STEGNER, A., ARSOUZE, T., TAUPIER-LETAGE, I., and BÉRANGER, K., 2014. Long-lived mesoscale eddies in the eastern Mediterranean Sea: Analysis of 20 years of AVISO geostrophic velocities. Journal of Geophysical Research: Oceans, 119(12), pp. 8603-8626.

POULAIN, P. M., 2001. Adriatic Sea surface circulation as derived from drifter data between 1990 and 1999. Journal of Marine Systems, 29(1-4), pp. 3-32.

POULAIN, P. M., MENNA, M., and MAURI, E., 2012. Surface geostrophic circulation of the Mediterranean Sea derived from drifter and satellite altimeter data. Journal of Physical Oceanography, 42(6), pp. 973-990.

ROBINSON, A. R., GOLNARAGHI, M., LESLIE, W. G., ARTEGIANI, A., HECHT, A., LAZZONI, E., MICHELATO, A., SANSONE, E., THEOCHARIS, A., and ÜNLÜATA, Ü., 1991. The eastern Mediterranean general circulation: features, structure and variability. Dynamics of Atmospheres and Oceans, 15(3-5), pp. 215-240.

ROBINSON, A. R., SELLSCHOPP, J., WARN-VARNAS, A., LESLIE, W. G., LOZANO, C. J., HALEY JR, P. J., ANDERSON, L.A. and LERMUSIAUX, P. F. J., 1999. The Atlantic ionian stream. Journal of Marine Systems, 20(1-4), pp. 129-156.

ROBINSON, A. R., LESLIE, W. G., THEOCHARIS, A., and LASCARATOS, A., 2001. Mediterranean Sea circulation. Ocean currents, 1(19).

ROUSSENOV, V., STANEV, E., ARTALE, V. and PINARDI, N., 1995. A seasonal model of the Mediterranean Sea circulation. J. Geophys. Res., 100(13), pp. 515-13,538.

VIGO, M. I., SEMPERE, M. D., CHAO, B. F., and TROTTINI, M., 2019. Mediterranean surface geostrophic circulation from satellite gravity and altimetry observations. In Meteorology and Climatology of the Mediterranean and Black Seas, pp. 269-285. Birkhäuser, Cham.

VIÚDEZ, Á., TINTORÉ, J., and HANEY, R. L., 1996. Circulation in the Alboran Sea as determined by quasi-synoptic hydrographic observations. Part I: Three-dimensional structure of the two anticyclonic gyres. Journal of Physical Oceanography, 26(5), pp. 684-705.

VIÚDEZ, A., PINOT, J. M., and HANEY, R. L., 1998. On the upper layer circulation in the Alboran Sea. Journal of Geophysical Research: Oceans, 103(C10), pp. 21653-21666. 